\title{
SOBRE EL CONCEPTO ERIUGENIANO DE FILOSOFÍA ${ }^{1}$
}

\author{
José Luis Cantón Alonso \\ Universidad de Córdoba
}

\section{RESUMEN}

Este artículo pretende esbozar algunos rasgos de la evolución de la idea misma de filosofía en el pensamiento de Escoto Eriúgena. Razón y unidad, por un lado, e intelecto e infinitud, por otro, son los elementos definitorios de los dos tramos que hemos diferenciado en ese proceso.

Palabras clave: Escoto Eriúgena, razón, intelecto, dialéctica, infinitud.

\section{ABSTRACT}

In this paper we try to study some aspects in the evolution of the concept of philosophy in Eriugena's thought. Two moments that have been differentiated, are mainly defined by the concepts of reason and unity, and by those of intellect and infinity respectively:

Key words: Scottus Eriugena, reason, intellect, dialectic, infinity.

La pregunta «¿Qué es filosofía?», aun en el caso de ir referida a un autor muy alejado de nuestra actualidad, es algo que desborda los límites de la erudición historiográfica. Pesan sobre ella los compromisos y problemas del presente que la formula, y que así espera ganar alguna claridad respecto a sí mismo. Por eso, la cuestión no persigue tanto qué decía tal autor que era o debía ser la filosofía, sino en qué medida y de qué manera lo que él hacía guarda relación viva con esa aventura intelectual en la que aún hoy, bajo el mismo nombre, estamos empeñados.

No vamos, pues, tras la identificación de un sector del saber, sino que más bien exploramos indicios a partir de los cuales reconstruir ese modo o actitud que impregna el trabajo intelectual eriugeniano. «Filosofía» nombraría aquí el modo del saber en general. Sería, pues, un concepto fundamentalmente modal. Y propio de los modos es la modestia: no suelen llamar la atención sobre sí. Sin embargo, quizá, en el discurso filosófico tenga que darse un grado especial de manifestación del modo, como si del filósofo hubiera que esperar no sólo que haga lo que hace sino que, además, esté en condiciones de dar razón de su propia tarea. Por eso, al carácter modal de lo filosófico

1 Las referencias a la obra de Escoto Eriúgena las haremos conforme a las ediciones críticas de sus obras (menos Periphyseon V), cuyos datos de identificación editorial aparecerán en la primera mención; indicaremos a continuación entre paréntesis o corchetes la referencia según PL 122. 
habría que añadir esê esfuerzo de autoconciencia: en consecuencia, filosofía sería algo así como un saber del saber, e, inseparablemente, un saber del no-saber.

Pero esta autoconciencia es en cierto sentido parasitaria: ni nace de sí misma ni su crecimiento es espontáneo. Eșa reflexión es respuesta del sujeto a su propia experiencia racional con las cosas. Por eso, quizá, la forma de autoconciencia más madura haya que buscarla en las últimas palabras de un autor, aquéllas en las que la propia ejercitación del saber ha ido redondeando los perfilados conceptos propios del entusiasmo inicial de una voluntad que todavía no se ha medido suficientemente con la realidad. Dado el carácter aventurado de la empresa filosófica y la constitución laberíntica del espacio en que ha de realizarse, cosas ambas a las que nuestro autor es especialmente sensible, ${ }^{2}$ las seguridades con que se cuenta en el punto de partida son mínimas: en el comienzo quizá no haya más que el coraje de una voluntad que apuesta confiada por la inteligibilidad del mundo y el sentido de la existencia. La imprevisible trayectoria de este incierto peregrinaje irá ajustando la apuesta de partida a las dimensiones de lo racionalmente posible.

Desde estos supuestos, y sin pretender sostener ninguna discontinuidad abrupta en la evolución intelectual del Eriúgena, creo que hay elementos que permiten apreciar significativas diferencias entre la autoconciencia filosófica que se expresa en sus primeros escritos, el De praedestinatione y las Annotationes in Marcianum, y la que podemos reconstruir a partir del Periphyseon y los trabajos que le siguen, las Expositiones in Ierarchiam coelestem, la Homilía y el Comentario sobre el Evangelio de Juan. La radical asimilación del apofatismo dionisiano y la elaboración de una finísima teoría del hombre como imago Dei a partir de la lectura de Gregorio de Nisa y Máximo Confesor son algunos de los factores que de manera decisiva han contribuido a dibujar la última figura que ha tomado la conciencia filosófica del Eriúgena. Nuestro propósito aquí no es otro que el de esbozar alguno de los rasgos que caracterizan esos dos momentos.

\section{POSICIONES INICIALES: DE PRAEDESTINATIONE Y ANNOTATIONES IN MARCIANUM}

Estas dos obras nos ponen ante un Eriúgena inmerso por completo en el programa de rehabilitación de las artes liberales definido por Alcuino. Sin embargo, ese programa que reclama las artes dentro de la economía intelectual del cristianismo, deja por determinar la medida exacta de su juego y funcionalidad. Lo cierto es que, a juzgar por las disputas teológicas que se desatan en la época (Gotescalco, por ejemplo, no es ajeno al proyecto de Alcuino), no parece que de la adopción teológica de las artes haya resultado un estado de concordia doctrinal ni se haya hecho realidad la deseada unanimitas. La confianza de nuestro autor en el valor de las artes va ganando intensidad a medida que se reconoce asentada en una fundamentación sólida, lo que finalmente proporcionará seguridad y rigor a su aplicación. Y, en este sentido, el De nuptiis Philologiae et Mercurii de Marciano Capella le ofrece formas y contenidos de especial importancia. Probablemente descubre ahí que las artes y su.aplicación son indisociables de una determinada concepción metafísica, de

2 Cf. Periphyseon IV, (ed. E. Jeauneau), Dublín, 1995, p. 4, línea 28-p. 6- lín. 22 (743 C-744 B); V, 1010 B. Aspectos muy interesantes relativos a esta «lógica biográfica» que subyace y anima el trabajo intelectual eriugeniano pueden encontrarse en Jeauneau, E,, Quattre thèmes érigéniennes, Montréal-Paris, 1978. 
manera que fuera de ésta pueden convertirse en fuente de imprevisibles monstruosidades doctrinales. El interés y extensión con que comenta los episodios de la alegoría de las bodas muestra esa voluntad de poner las artes y su ejercicio sobre la base de un fundamento adecuado. ${ }^{3}$

El De Praedestinatione es ya una aplicación de las artes en el ámbito de ese compromiso metafísico de carácter genéricamente neoplatónico: allí se aclaran y precisan las posiciones definidas en las Annotationes, con las que guarda perfecta sintonía. ${ }^{4}$

Ya Alcuino justificaba la apropiación de las artes a título de gradus en el ascenso contemplativo del alma a través de la penetración intelectiva de las Escrituras. ${ }^{5}$ El Eriúgena de estos primeros escritos refuerza esa misma tesis integrándola en el marco de una teoría explícita del hombre y de la razón: si las artes han de desempeñar ese papel es porque su pertenencia al hombre es esencial. ${ }^{6}$ En ese concepto de hombre la idea de sapientia tiene una importancia capital: ésta representa la plenitud de lo humano en la forma de conocimiento de Dios. La sabiduría constituye, pues, el telos de la naturaleza humana. ${ }^{7}$ Esta sabiduría es algo para lo que el hombre es naturalmente apto, pero que requiere el concurso de su esfuerzo. Ni la aspiración a la sabiduría ni la natural aptitud para ella han desaparecido con el pecado. ${ }^{8}$ La ratio es el modo específicamente humano de hacer efectiva esa aptitud. Claramente nos lo dice en el De praedestinatione: «An forte non est homini substantialiter ratio? Quis audeat hoc dicere, cum sit uera hominis diffinitio: homo est substantia rationalis sapientiae capax!». ${ }^{9}$ La racionalidad no puede, por ello, quedar marginada en un programa de formación espiritual y de investigación teológica. Representa una dimensión de lo humano irrenunciable. Y las artes son en primer lugar la expresión operativa de la razón, y su pertenencia al hombre es tan esencial como la razón misma. ${ }^{10}$ Pero, además, a través de las artes redescubre el alma su propio ser y su inmortalidad: gracias a ellas el alma echa raíces en lo eterno. ${ }^{11} \mathrm{El}$

3 Cf. Mathon, G., «Les formes et la signification de la pédagogie des arts libéraux au milieu du IX siècle. L'enseignement palatin de Jean Scot Erigène», en Arts libéraux et philosophie au Moyen Age, Montréal-Paris, 1969, pp. 47-64; Leonardi, C., «Martianus Capella et Jean Scot: nouvelle présentation d'un vieux problème», en Allard, G.H. (ed.), Jean Scot Écrivain, Montréal-París, 1986, pp. 187-207. Como muestra el prof. Leonardi (art. cit., p. 207) en la profunda asimilación eriugeniana del De nuptiis tiene lugar un hecho singular: una de las tradiciones espirituales de la Antigüedad pagana acaba siendo una referencia fundamental de la conciencia teológica de nuestro autor.

4 La redacción de las Annotationes in Marcianum parece posterior al De praedestinatione; pero, dado que en aquellas se plasman ideas que se han ido gestando en una prolongada actividad docente, resulta razonable, como sugiere $G$. Mathon (Art. cit., p. 63), estudiar este dictamen teológico a la luz de las posiciones filosóficas que en las Annotationes enmarcan su concepción y práctica de las artes.

5 Grammatica, en PL 101,853 A-954 A. Cf. Leonardi, C., Art. cit., pp.194-5.

6 Este carácter sólo se le reconoce a las artes liberales, en oposición a las mecánicas. Cf. Annotationes in Marcianum (ed. C. E. Lutz), Cambridge-Mass, 1939, p. 86, 1s.24-30.

7 «[...] ipsa rationali natura, quae ad inquirendum eum creata est» (De praedestinatione, [ed. G. Madec], Turnholt, $1978,12,51-2$ [361B] ); «[...] rationalem creaturam condidit ad se intelligendam, ut summo sui bono, hoc est contemplatione creatricis suae, frui posset» (Idem, 30, 136-8 [372D]). Siendo la sapientia la plenitud humana, es también la consumación del mundo: «Nihil enim finit mundum nisi sapientia» (Annotationes, 131, 8).

8 «Ut enim ignis invisibiliter omnem corpoream, ita naturale ingenium quod universitati rationabilis nature commune est omnibus viritim in hoc mundo nascentibus distribuitur mortalibus, ne et conditoris sui et naturalis dignitatis cognitione omnino priventur, sed semper interiore lumine illustrati et se ipsos et deum suum assidua veritatis indagine inquirunt» (Annotationes, 13, 12-8).

9 De praed., $50,72-4$.

10 «Omnes artes quibus rationalis anima utitur naturaliter omnibus hominibus inesse» (Annotationes, 27, 18-9).

11 Cf. Annotationes, 27, 15-22. 
concepto de filosofía con el que nuestro autor podría sentirse identificado consistiría precisamente en esto: el reconocimiento y aceptación de la racionalidad como modo propio de ser hombre, esto es, de encaminar la realidad humana hacia su plenitud. ${ }^{12}$ Este concepto de filosofía coincide materialmente con el cuerpo de las artes liberales, pero añade a éstas una dimensión teleológica y funcional que resulta fundamental: las artes son indisociales del fin al que la naturaleza humana está originalmente destinada. $^{13}$

Desde estas consideraciones la entusiasta y un tanto escandalosa declaración «Nemo intrat in caelum nisi per philosophiam ${ }^{14}$ debe entenderse en el sentido de que la razón y las artes no pueden ser apartadas del esfuerzo perfectivo del hombre; éste ha de ser propiamente un studium rationis. Esto mismo puede aplicarse a la identificación que, al amparo de san Agustín, establece entre uera philosophia y uera religio al comienzo del De praedestinatione: ${ }^{15}$ religión y filosofía son nombres de lo mismo, el proceso conducente a la plenitud humana en el encuentro contemplativo con Dios; el fin que ambas persiguen las identifica, lo que hace de ellas dimensiones indisociables de un único movimiento: la religión, "qua deus et humiliter colitur et rationabiliter inuestigatur», no puede en nombre de la dignidad humana acallar la razón para convertirse en un actitud reverencial ciega, ni el trabajo racional contribuye a la promoción humana si desatiende su última dimensión teológica. ${ }^{16}$

No hay, pues, motivo que justifique alguna reserva frente a la actividad racional y que pudiera recomendar o exigir alguna limitación externa de su juego. Allí donde se encuentren error o falsedad, ni la razón es responsable, ni su limitación es el remedio. La causa de las locuras y desviaciones de la razón está en otra parte: en la infidelidad del hombre a sí mismo, en el pecado. Aquí la razón está dislocada: su finalidad propia ha desaparecido del horizonte de su actividad y parece prestarse indiferentemente a cualquier servicio: la razón se convierte en instrumento. ${ }^{17}$ Ausente de ella la unidad que le venía dada por el fin natural, se presenta fragmentada y dispersa en un montón de recursos incoherentes. ${ }^{18}$ Por eso, todo el cuidado que ha de acompañar al ejercicio racional ha de ir orientado a la restauración y consolidación de su natural compromiso formativo y teológico.

12 Cf. De praed., 5, 4-16 (357C-358A). La identificación entre «philosophia» $y$ «sapientiae studium» y, en ese mismo párrafo, la presentación de aquélla como depositaria o matriz de «omnis piae perfectaeque doctrinae modus» justifican suficientemente esta idea.

13 De esta manera va perdiendo peso su consideración utilitaria y va consolidándose su carácter esencial e incluso normativo. Cf. Mathon, G., Art. cit., 58.

14 Annotationes, 64, 23-4.

15 «Si enim, ut ait sanctus Augustinus, creditur et docetur, quod est humanae salutis caput, non aliam esse philosophiam, id est sapientiae studium, et aliam religionem, cum hi quorum doctrinam non approbamus nec sacramenta nobiscum communicat, quid est aliud de philosophia tractare, nisi uerae religionis, qua summa et principalis omnium rerum causa, deus, et humiliter colitur et rationabiliter inuestigatur, regulas exponere? Conficitur inde ueram esse philosophiam ueram religionem conuersimque ueram religionem esse ueram philosophiam» (De praed., 5, 9-18 [357C-358A] ).

16 Aunque el papel que explícitamente se le asigna a la filosofía, en esta declaración inicial, parece limitarse a la labor un tanto externa de "uerae religionis regulas exponere», hay que suponer necesariamente que la religión misma es racional y racional ha de ser también el modo adecuado de su ejercicio.

17 En esto consiste el estatuto de «bien medio» que el Eriúgena, siguiendo a San Agustín, le reconoce a la razón dentro del régimen mundano de existencia. Cfr. De praed., 45, 17-37 (382BD).

18 La figura de la serpiente representa ya en las Annotationes el estado y actividad de esa razón instrumental que se ha tornado incapaz de elevarse hacia arriba y se arrastra sinuosa entre las cosas: «Per serpentem, sophisticas subtilitates intellige» (Annotationes, 82, 90). 
El modo en que este vínculo esencial de la razón se hace efectivo en las artes es la dialéctica. En ella encontramos el momento más estrictamente filosófico de la razón; y ello hasta el punto de quedar identificada con la filosofía misma. ${ }^{19}$ Sólo la dialéctica proporciona y asegura la universalidad a que todo saber aspira y que lo constituye en regla: «Nihil regulare potest esse in caeteris disciplinis, nisi fuerit dialecticae adjunctum». ${ }^{20}$ Pero la dialéctica no sólo da a las artes, de esta manera, una cierta unidad formal y operatoria, sino que hace del saber un cuerpo orgánico, un sistema, dentro del cual hay estructura y jerarquía. Limitándonos al ámbito del trivium, lógicamente dominante en un trabajo cuya materia viene dada fundamentalmente por las Sagradas Escrituras y los textos de los Padres, el Eriúgena proclama de muchas maneras la necesidad de la tutela y vigilancia dialéctica de las artes del lenguaje: así lo impone el principio agustiniano de «in uerbis uerum amare non uerba» ${ }^{21}$ y eso le lleva a definir la dialéctica como «inquisitio ueritatis mundanae locutionis». ${ }^{22} \mathrm{El}$ desconocimiento de ese estatuto de subordinación dialéctica del lenguaje está a la base de muchas desviaciones teológicas. Dentro de esta genérica tutela la retórica es objeto de especial atención y cuidado.

Esta función tutelar y normativa de la dialéctica no es sino la operatividad discursiva de ciertos contenidos a los que el alma está esencialmente vinculada. ${ }^{23}$ De entre estos es la unidad el concepto o principio que con más fuerza se hace notar en el De praedestinatione: aquí la unidad aparece como horizonte y objetivo último de la dialéctica, objetivo que orienta y ordena el quehacer de todas las demás artes. ${ }^{24} \mathrm{La}$ unidad es la nota peculiar del pathos que impregna esta obra.

La unidad de las artes es, finalmente, la unidad de lo verdadero a la que todas cooperan bajo la dirección de la dialéctica. «Disputandi disciplina, quae est ueritas». ${ }^{25}$ hasta tal punto es estrecha la relación entre dialéctica y verdad que el Eriúgena no duda en identificarlas. Dada la pertenencia esencial de las artes al alma, éstas a través del proceso disciplinar de su desarrollo no son sino la eclosión gradual de la verdad que habita en la intimidad del alma. La verdad está ya, pues, de antemano y precede al trabajo racional. El fondo del alma y las Escrituras son su lugar primario. Pero el modo en que ahí se encuentra necesita de los cuidados de la razón para madurar y hacerse eficaz en su manifestación pública. La razón, y la dialéctica como su reglamento básico, aparecen como el órgano manifestativo de la verdad.

19 «Quae [philosophia], dum multifariam diuersisque modis diuidatur, bis binas tamen partes principales ad omnem quaestionem soluendam necessariam habere dinoscitur, quae graecis placuit nominari $\triangle$ IAIPETIKH, OPISTIKH, AПO$\triangle I K T I K H$, ANA $\Lambda$ YTIKH, easdemque latialiter possumus dicere diuisoriam, deffinitiuam, demonstratiuam, resolutiuam» (De praed., 5, 18-24 [358A]).

20 Annotationes, 89, 12-3. «Omne autem quod universaliter non invenitur pro certa regula teneri vera ratione non sinit» (Idem, 103, 15-7).

21 Cf. De praed., 4, 37-55 (386B-387B).

22 Annotationes, $90,11$.

23 En la medida en que ella opera con y desde los contenidos inmediatos y naturales de la mente, las communes animi conceptiones. Cf., D'Onofrio, G., «'Disputandi disciplina'- Procédés dialectiques et 'logica vetus' dans le langage philosophique de Jean Scot», en Allard, G.H. (ed.), Jean Scot Écrivain, Montréal-Paris, 1986, pp. $244-5$.

24 Como dice G. Madec, en el De praedestinatione el agustinismo de la predestinación es reducido en favor del agustinismo de la simplicidad divina. Cf. Madec, G., «L'augustinisme de Jean Scot dans le 'de Praedestinatione'», en Roques, R. (ed.), Jean Scot Erigène et l'histoire de la philosophie, Paris, 1977, p.189.

25 De praed, 6, 32-3 (358B). 
Ahora bien, dada la somnolencia y pereza que aqueja a la razón en su existencia terrenal, se hace a veces necesario el estímulo de la herejía para que se active esa uis rationis que a través de las artes va despejando el espacio de emergencia de la verdad, la aurora del dies dei. ${ }^{26}$ Desde aquí podemos reinterpretar la identificación entre uera philosophia y uera religio: ambas acceden al rango de "uera» en virtud y como resultado de su coincidencia misma: la verdad de que la religión es depositaria precisa de la razón para consumar y consolidar su manifestación.

En el De praedestinatione el Eriúgena se muestra especialmente sensible a la vulnerabilidad de una fe no asistida racionalmente. Y los peligros más graves a los que está expuesta proceden precisamente de la intervención irregular de las artes: irregular porque se sustrae a la tutela y administración de la dialéctica. ${ }^{27}$ Pero si en ausencia de ésta, las artes pueden convertirse en instrumentos de la malicia que pervierten y oscurecen la fe, también es verdad que la dialéctica por sí sola, sin el auxilio de las otras artes, estaría incapacitada para dar satisfacción a esa exigencia de manifestación, pues a través de ellas tiene acceso a la materia manifestativa que le viene dada por el lenguaje y lo sensible.

A juzgar por la atención casi exclusiva que en el De praedestinatione se presta a las artes del Trivium, parece que el ámbito de manifestación queda limitado al lenguaje. Sin embargo, intencionalmente, la razón aspira a hacer coincidir el ámbito de manifestación con la realidad en su conjunto. Los saberes de las cosas, lo que llamamos el Quadrivium, no son ajenos a esta función ni a la administración dialéctica: en ellos se hace también presente de manera orgánica y articulada la unidad teológica. ${ }^{28}$ En última instancia la figura de la verdad, el mediodía del dies dei, sería el sistema universal del saber.

\section{REDEFINICIÓN DE LA FILOSOFÍA A PARTIR DEL PERIPHYSEON}

La lectura de los padres griegos, Pseudo-Dionisio, Máximo Confesor y Gregorio de Nisa ofrece a nuestro autor elementos con los que articular y desarrollar de manera más precisa sus posiciones de fondo. De esta manera va alterando las coordenadas doctrinales básicas, y de manera suave se va produciendo una redefinición de las categorías fundamentales de su pensamiento. Todo ello se traducirá finalmente en una modificación del estatuto de la ratio y del papel de la dialéctica; en definitiva, en una nueva figura de la autoconciencia filosófica.

26 «Sunt enim innumerabiles in sancta ecclesia deo probati uiri; sed manifesti uiri non fiunt inter nos, quamdiu imperitiae nostrae tenebris delectati dormire malumus quam lucem ueritatis intueri. Quapropter multi, ut diem dei uideant et gaudeant, per haereticos de somno excitantur. Utamur ergo etiam haereticis, non ut eorum approbemus errores, sed ut catholicam disciplinam aduersus eorum insidias asserentes uigilantiores et cautiores simus, etiam si eos ad salutem reuocare non possimus» (De praed., 7, 67-75 [359AB]).

27 Y esto es lo que caracteriza a las herejías más insidiosas, que son en última instancia producto de la argumentosa malitia (De praed., 8, 80 [358B]) o diabolica subtilitas (Idenn, 29, 95 [371D]).

28 Esta especial sensibilidad hacia la unidad se expresa de mucha maneras: la preferencia que en el comentario al De nuptiis muestra por la música es una de ellas: la singular etimología que hace de «armonia» interpretándola como «adunatio» lo ratifica (Jeauneau, E. [ed.], «Le commentaire érigénien sur Martianus Capella De nuptiis Lib. I.», en Quattre thèmes érigéniens, Montréal-Paris, 1978, p. 119). 
Si la fase incial de su pensamiento estaba marcada por el pathos de la unidad, a partir de ahora es la infinitud el rasgo determinante del nuevo pathos. Este concepto adquiere una radicalidad extrema y va a situarse como horizonte y referencia constante de todo su pensamiento. No hay concepto en el Eriúgena que no se resienta del efecto de su ingreso en el nuevo juego de la infinitud.

El pensamiento de la infinitud divina resulta para la razón una continua fuente de aporías y paradojas. La ausencia en Dios de toda determinación lo pone absolutamente fuera de toda forma de conocimiento, pues éste tiene su operatividad limitada al ámbito de la finitud, la determinación y la oposición. El colmo de esta posición está expresado en la conocida tesis de la autoignorancia divina. ${ }^{29}$ Ello le lleva a aceptar como nombre casi propio de la infinitud divina, el de «nihil», nombre en el que se reconoce su transcendencia infinita, la imposibilidad de una captación positiva y de una exposición afirmativa del mismo. Ahora bien, esta nada infinita no puede tolerar un exterior que lo limite: el universo de las determinaciones y los nombres ha de ser pensado como algo integrado en la infinitud misma innombrable. La nada incorpora y contiene, pues, el omnia de las creaturas. Y este es el lugar del gran misterio: la unidad de nada y todo en el seno de la infinitud divina; es el misterio al mismo tiempo de la creación y de la constitución trinitaria de la divinidad.$^{30} \mathrm{El}$ misterio, racionalmente irreductible, puede ser vislumbrado a través de ciertas similitudines: la difusiva eficacia de la bondad y la exteriorización objetivadora de la expresión son algunos ejemplos. La nada es una infinitud que se expresa eficazmente en el universo múltiple de las cosas. Estas quedan así indisolublemente ligadas a la divinidad que a través de ellas se crea, manifiestándose a sí misma. ${ }^{31}$

En este proceso automanifestativo que toma cuerpo en el orden creado, la función del hombre en su condición de imago Dei es clave. La multiplicación y difusión expresiva frustraría, en la forma de fragmentación y dispersión, su intención manifestativa si finalmente no resultara de ella algo así como una imagen de lo manifestado, esto es, una multiplicidad orgánica y sintácticamente articulada. La mediación humana en el juego manifestativo de la divinidad consiste precisamente en aportar unidad y orden a la multiplicidad resultante de la expresión. Su título definitorio de imago Dei hay que entenderlo ahora como indicación de esta tarea unificadora: omnium creaturarum adunatio. ${ }^{32}$ Estrictamente sólo en el hombre y por su mediación la creación es efectivamente teofanía: ${ }^{33}$ sin su concurso lo creado quedaría en un estado de dispersión inexpresiva.

Esta competencia específica diferencia radicalmente al hombre del resto de lo creado, en el sentido de que su ser no está sujeto a determinación finita alguna, sino que arraiga directamente en

29 La imposibilidad de una autoconciencia inmediata en Dios radica en el carácter absoluto o universal de su infinitud: «uniuersaliter infinitus», «sibi ipsi infinitus» (Periphyseon II. [ed. I.P. Sheldon-Williams], Dublín, 1972, pp. 138 ss [587B ss]).

30 En sí misma «plus quam unitas est et plus quam trinitas» (Periph. II, 200, 34 [614C]).

31 Cf. Periphyseon I. (ed. I.P. Sheldon-Williams), Dublín, 1968, 66, 21-5 (455AB). El carácter fundamentalmente expresivo de esta causalidad creativa estrecha c intensifica el vínvulo entre creador y creatura hasta el punto de no ser dos sino uno y lo mismo: «Non duo a seipsis distantia debemus intelligere Deum et creaturam, sed unum et id ipsum» (Periphyseon III. [Ed. I.P. Sheldon-Williams], Dublín, 1981, 160, 37 [678C]).

32 Periph. II, 28, 18-22 (536AB).

33 Teofanía es algo más que presencia bruta de Dios en las creaturas; ese concepto contiene una referencia al hombre como lugar en que esa presencia se consuma. A este respecto puede verse mi artículo «Intelecto y teofanía en Escoto Eriúgena», en Actas del I Congreso nacional de Filosofia Medieval, Zaragoza, 1992, pp. 213-25. 
la infinitud divina. ${ }^{34} \mathrm{El}$ hombre es, paradójicamente, infinitud creada: su ser desborda en todo caso las determinaciones en que puede encontrarse inmerso. En su interior se encuentra reflejada la misteriosa unidad de nada y todo que pertenecía a la infinitud divina. ${ }^{35}$ Esto va a exigir una concepción del alma más articulada y diferenciada que la que podíamos encontrar en la fase anterior, y nuestro autor la encontrará ya muy elaborada en los textos de Máximo y Gregorio de Nyssa. El lugar eminente de esta infinitud es el intelecto, en él radica la condición específica de imagen de Dios. ${ }^{36} \mathrm{La}$ importancia y relieve sistemático que el intelecto registra a partir de Periphyseon contrasta con el escaso juego que esta dimensión del alma presenta en el De praedestinatione: si allí dominaba la concepción del hombre como substantialiter ratio, a partir de aquí el hombre es preferentemente referido bajo expresiones del tipo «intellectualis et rationalis natura», etc. ${ }^{37}$ En todo caso la dimensión infinita de la imagen de Dios la detenta, cuida y administra el intelecto; él es el guardián de la infinitud. ${ }^{38}$

Del mismo modo que la realidad divina se constituye trinitariamente y se manifesta en la difusión creadora, el intelecto se hace presente a sí mismo en el descenso expresivo que al mismo tiempo revela su constitución y funcionalidad trinitaria: el alma es la unidad de intellectus-ratio-sensus. Estas tres partes no son sino momentos operativamente diferenciables del alma en el logro de su destino natural, que sigue siendo sapientia o dei contemplatio. Pero esto es ahora asunto del intelecto. Este objetivo último va a quedar también repercutido por la infinitud: la diferencia entre sapientia y scientia se intensifica, y la figura propia de aquélla no es tanto la de la ciencia perfecta, cuanto la de la ignorancia dei. ${ }^{39} \mathrm{La}$ discontinuidad lógica entre sapientia y scientia refleja la peculiar relación entre intellectus y ratio. Y esta problemática relación, imagen y transposición de la misteriosa relación entre el dios infinito y la finitud del orden creado, es propiamente el lugar de la filosofía: a ella le corresponde hacerse cargo de la unidad de lo finito y lo infinito, a ella le compete asumir las demandas del intelecto desde los limitados recursos de la razón; esto es, hacer efectiva la conjunción expresada en la fórmula «intellectualis et rationalis natura». Será, por lo tanto, tarea suya definir, articular y administrar el papel de la scientia en el logro de la sapientia, porque la consideración racional de las cosas sigue siendo el momento irrenunciable de la elevación teo-

34 «Inter Deum et humanitatem nullum interstitium constitutum est» (Periphyseon, V. 941C). Cf. también Expositiones in Ierarchiam coelestem. (Ed. J. Barbet),Turnholt, 1975, p.75.

35 Los caracteres del alma que delatan su condición de imago Dei son precisamente aquellos en los que transparece su infinitud. «Doubus autem modis maxime humanam animam ad imaginem Dei factam cognoscimus. Primo quidem quod, sicut Deus per omnia quae sunt diffunditur, et a nullo eorum potest comprehendi, ita anima totum sui corporis organum penetrat, ab eo tamen concludi non ualet; secundo uero quod, quemadmodun de Deo praedicatur solummodo esse, nullo modo autem diffinitur quid sit, ita humana anima tantummodo intelligitur esse, quid autem sit, nec illa ipsa, nec alia creatura intelligit» (Periphyseon IV. [ed. E. Jeauneau], Dublín, 1995, 112, 1-8 [788A]).

36 «Et animus quidem, in quo tota animae uirtus constat, ad imaginem dei factus, et summi boni speculum, quoniam in eo diuinae essentiae incomprehensibilis forma ineffabili et incomprehensibili modo resultat» (Periph., $\mathrm{V}, 118$, 3$6[790 \mathrm{C}])$.

37 Cf. Periph., III, 284 (732B-733A); Periph., IV, 30 (754BD); Idem, 74 (772BC).

38 Tras el pecado, permanece allí activa la infinitud bajo la figura de un deseo inextinguible. La presión de la infinitud divina en el deseo hace de la existencia una inquisitio veritatis infinita. "Quoniam infinitum est quod querit, necesse est ut infinite querat» (Expositones, 87, 38). «Infinitus enim infinite, etiam in purgatissimis mentibus, formatur» (Commentaire sur l'évangile de Jean [ed. E. Jeauneau], Paris, 1972, 182, $42-3$ [312B]).

39 Cf. Periph., I, 190, 27-33 (510B). 
lógica. Esta discontinuidad en modo alguno puede ser una invitación a la abdicación racional en la pretensión de habilitar caminos o atajos a la sabiduría de índole no-racional. ${ }^{40}$

La sola ratio ${ }^{41}$ es incapaz de dar satisfacción a la aspiración teológica de infinito que anida en el alma. La limitación que aquí experimenta la razón no procede de ningún déficit reglamentario 0 lógico: la rectitud de su proceder, como conformidad con su reglamento dialéctico inmanente, es precisamente lo que la retiene en la finitud categorial.

La vocación de infinitud penetra en la actividad racional en el momento en que la razón opera en régimen de subordinación respecto al intelecto o como órgano del mismo. ${ }^{42}$ En este régimen la rectitud racional no va a ser sólo conformidad con su ordenación reglamentaria inmanente, sino antes que nada aplicación de su esfuerzo a las demandas de infinitud del intelecto. Porque el intelecto aparece como una instancia fundamentalmente demandante: el saber o pre-saber de que es depositario se hace efectivo en la forma de demanda, que se traduce en inquisitio racional. El intelecto guarda en sí esa memoria esencial de lo infinito que le permite ejercer esa presión constante sobre la razón. ${ }^{43}$ En respuesta a esa demanda del intelecto activa la razón el poder extraordinario de la negación: a diferencia del carácter afirmativo de la razón natural, la negación se convierte en el órgano y modo específico de la razón teológica. ${ }^{44}$ En virtud de este nuevo poder, que sólo la conexión con el intelecto mantiene vivo, la razón puede desempeñar una eficaz función en un movimiento de trayectoria vertical, y no sólo horizontal o en superficie como le es propio en su ordinario quehacer afirmativo. Pero la negación no es una vía rápida alternativa, que salve las penalidades del trabajo racional, sino una posibilidad de la razón que sólo precipita cuando ésta es puesta intelectualmente en el límite de su capacidad.

En este contexto, los diversos saberes que el trabajo racional va produciendo (o haciendo manifiestos), al tiempo que se definen por las características propias de aquellas áreas de realidad que tienen por objeto, refieren también y sobre todo los diversos grados del ascenso intelectual, «ascensionis gradus». 45 Por ello, esta dimensión anagógica ha de reconocerse también en la célebre "quadriformis sophiae diuisio» propuesta en el tercer libro del Periphyseon. Dice allí así; «Et est quidem prima ПPAKTIKH, actiua; secunda, $Ф Y \Sigma I K H$, naturalis; tertia $\Theta E O \Lambda O \Gamma I A$, quae de Deo disputat; quarta $\Lambda O Г I K H$, rationalis, quae ostendit, quibus regulis de unaquaque trium alianum sophiae partium disputandum». ${ }^{46}$

40 La necesidad de esta presencia activa de la razón en la sabiduría está de alguna manera recogida en la calificación de sapientia y scientia como «species rationis» (Cf. Periph., III, 48, 28-50, 8 [629AB]).

41 Esta tiene limitada su competencia al ámbito de la necesidad natural: «Sola ratio et naturalis necesitas» (Periph., $V, 890 \mathrm{~B})$.

42 Cf. Periph. II, 122, 3-8 (579CD).

43 Ese es el poder de esa virtus theologica innata a la que nuestro autor se refiere frecuentemente: «[...] theologia, illa uidelicet uirtus, que naturaliter humanis inest mentibus ad diuinas rationes querendas, inuestigandas, contemplandas, amandas [...]» (Expositiones, 23, 129-31 [146A] ). «[...] ipsa sapientissima theologia, siue quedam gnostica uirtus, sit angelicis humanisque mentibus naturaliter insita» (Expositiones, 76, 457-8). «Insitum sibi divinum lumen» (Homélie sur le Prologue de Jean [ed. E. Jeauneau], Paris, 1969, 266, 15-6 [290D]).

44 «In theologicis siquidem regulis ad inuestigandam diuinae naturae sublimitatem et incomprehensibilitatem plus negationis quam affirmationis uirtus ualet» (Periph., III, 174, 37-176, 1 [684D])

45 Cf. Periph., V, $1020 \mathrm{BD}$.

46 Periph., III, 222, 13-21 (705B). Y sigue así: «Quarum una uirtutes, quibus supplantantur uitia penitusque eradicantur, inuestigat; altera rationes naturarum siue in causis siue in effectibus; tertia quid de una omnium causa quae Deus est pie debeat aestimari; quomodo autem et uirtus et natura et Deus rationabiliter quaeritur, quarta ut diximus edocet diligenterque considerat». 
De las cuatro partes que ahí distingue (actiua, naturalis, theologia y rationalis) las tres primeras (actiua, naturalis y theologia) puede considerarse que describen la secuencia del proceso de formación espiritual. El carácter secuencial y gradual de esa clasificación lo vemos reforzado en las Expositiones ${ }^{47}$ y en los trabajos sobre el Evangelio de Juan. ${ }^{48}$ La cuarta parte, logica o rationalis, no es un grado dentro de este proceso, sino el reglamento racional cuyo seguimiento asegura la validez de cada una de las partes anteriores. Bajo el nombre de «logica» o "rationalis» refiere aquí lo que por lo general venía llamándose «dialectica», la «disputandi disciplina». A pesar de su excepcionalidad, no deja de ser significativo este cambio terminológico. En cualquier caso, parece que dentro de la dialéctica empieza a producirse una cierta diferenciación: por una parte, la lógica, que cubriría la preceptiva regular que gobierna internamente los saberes; y, por otro lado, de manera cada vez más definida, algo así como la ley del proceso ascendente de la realidad que dispone y ordena los saberes en la forma de un progreso gradual. Este resto dialéctico, no estrictamente lógico ni traducible reglamentariamente, es una exigencia intelectual que sobrepuja a la razón encaminándola hacia la sapientia. Empieza así a aparecer un doble concepto de dialéctica, ${ }^{49}$ que se correspondería con los dos sentidos de rectitud referidos antes. Esta doble dialéctica, racional e intelectual, gobernaría los procesos de afirmación y negación respectivamente. La dialéctica regularracional cubriría competencias horizontales del saber, mientras la dialéctica intelectual dispondría el trabajo racional en trayectoria vertical, con orientación teológica.

La dialéctica lógica es inepta para la verticalidad, para realizar saltos de nivel. ${ }^{50}$ Estos vienen exigidos por la dialéctica noética, y a ellos responde la razón mediante la negación. Y es aquí donde está el problema: en el modo en que la razón puede permanecer activa y productiva en la negación, sin cancelarse a sí misma en el silencio; esto es, cómo puede hacerse cargo de la infinitud. La vía de solución no está en sustituir la lógica por la noética, la afirmación por la negación, la finitud por la infinitud, la palabra por el silencio, sino en subordinar aquélla a éste, en hacer de aquélla órgano de éste. En ese juego la dialéctica noética no hace sino mantener el trabajo racional en el horizonte de una referencia infinita.

Lo que esta dialéctica noética prescribe a la razón no es otra cosa que la adecuación de su trabajo al ritmo vivo de la realidad misma, ritmo con el cual el intelecto está naturalmente acompasado. El contenido de esta dialéctica noética no es otro que la certeza inmediata de que la vida de lo infinito tiene lugar al ritmo de división y unificación, de expansión y contracción, de diairesis y analysis. ${ }^{51}$ Así, en dependencia del intelecto, la ratio ingresa en la tarea de la verdad; esto es, contribuye al acontecimiento teofánico.

Bajo la tutela intelectual la ratio encara la realidad en una nueva clave: las cosas y sus determinaciones se presentan ahora como la multiforme expresión de la vida de la divinidad, constitu-

47 Cf. Expositiones, 156, 187-209 (227C-228A).

48 Cf. Comment., 184, 44-188, 75 (312B-313A); Homélie, 270, 5-272, 17 (291BC).

49 Cf. D'Onofrio, G., Art. cit., 246 ss.

50 Aunque el Eriúgena presenta normalmente la lógica de géneros, especies e individuos en términos de verticalidad y jerarquía, en el marco de la inquisitio theologica eso se atenúa y todo el ámbito de dominio lógico se presenta homogéneo sobre la base de su carácter óntico y categorial.

51 En virtud de la subordinación a esta prescripción la razón sabe que sus operaciones han de realizarse dentro del juego de ese doble movimiento: «Non enim, ut praediximus, recta ratio de diuisione permittit absolute tractare et ANAAYTIKAM intermittere, sed de ambadus conexim ueritatem iubet consulere» (Periph., II, 20, 12-4 [532A]). 
yendo el espacio y contenido manifestativo a través del cual se declara la alteridad irreductible de la infinitud divina. La referencia infinita que emerge en toda determinación añade al momento lógico de la razón una dimensión hermenéutica, en virtud de la cual reconoce aquélla su incapacidad para proferir la última palabra.

En el marco de esta intención teológica, todas las palabras que la razón articula ${ }^{52}$ están atravesadas por la negación. Y en esto consiste el régimen metafórico del decir teológico, un decir que hace de las determinaciones resortes para su propia superación intelectiva, para orientar y mantener la mirada en lo infinito. ${ }^{53}$

Esta síntesis de afirmación y negación que se da en el interior de toda palabra teológicamente válida es completamente diferente de la relación externa de afirmación y negación que se produce en el discurso categorial, y nos introduce en un juego discursivo para el que el mejor calificativo quizá sea el de poético. ${ }^{54}$ Dar voz a lo inefable, haciendo de la palabra espacio de resonancia del silencio es convertir la palabra en camino, combatiendo así la inercia sedentaria del carnaliter cogitare. Sólo la palabra poética es anagógica: sólo en ella, por su carácter explícitamente no representativo, se conjura la tentación idolátrica de identificar el nombre y lo nombrado, y se afirma la diferencia inconmensurable de esto. ${ }^{55}$

Pero la palabra poética no es materialmente diferente de la palabra ordinaria; la diferencia está en el modo de proferirla y acogerla: y este modo es el intelecto el que lo determina. Dicho de otra manera, la sapientia, ese saber teológico a que el intelecto naturalmente aspira, es en cierto sentido la scientia misma, sólo que poéticamente proferida o comprendida; o lo que es lo mismo, ciencia que se ha curado de la ilusión de verdad y sabe que su valor no puede ser sino el de apertura a una infinitud siempre transcendente. Así, la presión del intelecto convierte la razón lógica en razón poética.

La virtualidad anagógica del decir poético se hace efectiva en el transitus, otra de las dimensiones de la negación teológica. Más allá del valor exegético de este procedimiento retórico, ${ }^{56} \mathrm{el}$

52 Movida por una «quaedam necessitas ineffabilis naturae significandae» (Periph., I, 196, 10-1 [512C]).

53 Eso es lo que quieren indicar el prefijo «super» o la cláusula "plus quam» (Cf. Periph., l, 84, 1-14 [462CD]). Se trata en todo caso de un proceder discursivo transgresor del orden lógico. Esa es una de las razones de la preferencia que manifiesta por la simbología teológica desemejante y teratológica; cf. Roques, R., «Teratologie et théologie chez Jean Scot Erigène», en Libres sentiers vers l'érigénisme, Roma, 1975, pp. 13-43.

54 Aunque nuestro autor reconoce el carácter poético-didáctico de buena parte de la literatura teológica y también de las Escrituras (Cf. Expositiones, 24, 142-158 [146BC]: «[...] ita theologia, ueluti quedam poetria [...]»), no parece ir tan lejos como nosotros pretendemos: el carácter poético de la literatura sagrada sería dialécticamente reducible a concepto, «in rerum intelligibilium perfectam cognitioñem». Sin embargo, aunque no llega a tematizarlo, su propia práxis exegética parece entrañar el reconocimiento del carácter necesariamente poético, por supra-lógico o supra-conceptual, del decir teológico.

55 Cf. Expositiones, 36, 598 ss (157B ss).

56 El lugar donde más claramente se define y aplica el concepto exegético de transitus es Periph, V, 1008 B-1010 B. Pero también es ahí, a continuación, donde mejor se ve que el concepto de transitus excede ese estrecho ámbito metódico mostrando un inequívoco carácter anagógico, teológico y metafísico: «Et quis est iste, Domine, transitus tuus, nisi per infinitos contemplationis tuae gradus ascensus? Semper enim in intellectibus quaerentium et inuenientium te transitum facis. Quaereris enim ab eis semper, et semper inueniris, et non inueniris semper: inueniris quidem in tuis theophaniis, in quibus multipliciter, ueluti in quibusdam speculis, occurris mentibus intelligentium te, eo modo, quo te sinis intelligi, non quid es, sed quid non es, et quia es; non inueniris autem in tua superessentialitate, qua transis et exuperas omnem intellectum uolentem et ascendentem comprehendere te. Ministras igitur tuis praesentiam tuam ineffabibli quodam modo apparitionis tuae; transis ab eis incomprehensibili excelsitudine et infinitate essentiae tuae» (Idem, $1010 \mathrm{CD}$ ). Cf. Beierwaltes, W., «Language and Object. Reflexions on Eriugena's Valuation of the Function and Capacities of Language», en Allard, G.H.. (ed.), Jean Scot Écrivain, Montréal-Paris, 1986, pp. 223-8. 
Eriúgena refiere con el verbo «transeo» y derivados, por lo general, el movimiento de la realidad hacia su plenitud. Pues bien, la palabra poética es siempre palabra que pide otra palabra, que prepara otra palabra al despejar nuevos ámbitos intelectivos. El transitus o salto de nivel que de esta manera tiene lugar no está sujeto a lógica o disciplina regular alguna, no es un asunto que pueda ser técnicamente resuelto por la lógica de la sola razón: no hay propiamente una metodología del transitus. No obstante éste no es errático: se da la orientación que el ánimo en todo caso va dictando y que el Eriúgena enuncia en esa expresión paulina que bien podría ser considerada la protorregla intelectual: «Unusquisque suo sensu abundet» ${ }^{57}$ Este imperativo introduce la tensión poética en todo decir en respuesta a la demanda de infinito que brota del fondo del alma. La trayectoria vital que el seguimiento de este dictado intelectual va dibujando adopta la forma de un ascenso escalonado marcado por abruptos y radicales cambios, a través de los cuales transparece de forma cada vez más luminosa la infinitud divina en el rostro humano: crucifixión y muerte son formas con que nuestro autor gusta referir la radicalidad de esos saltos. ${ }^{58}$

Este movimiento ascendente a que va dando lugar la activa presencia del intelecto hace de la razón testigo de su propio devenir, la pone frente a sus propias vanidades. La experiencia del transitus y de la negación en general previene cualquier tentación absolutista de la razón. Y esta razón que sabe de su necesidad y al mismo tiempo de su limitación es la filosofía; la razón que se mide con las cosas y con el alma misma, y en este penoso proceso va descubriendo su lugar y su función; la razón que ajusta su quehacer a ese ritmo de división y unidad, de diairesis y analysis, que el corazón mismo de la realidad infinita va marcando y al que el intelecto naturalmente corresponde.

José Luis Cantón Alonso
Dpto. de Filosofía
Facultad de Filosofía y Letras
Plza. Cardenal Salazar, 3. E-14071 CóRDOBA

